and comprehensive publications such as these could help much towards standardization of terminology in a field where there is already some tendency to laxity, for example, in the indiscriminate use of the terms 'curing' and 'vulcanization' and in the omission. of the prefix 'poly-' from the name of a monomer when speaking of the polymerized substance. The checking of chemical names in the individual chapters appears to have been carefully done; but attention may be directed to trimethylpropane (presumably for trimethylol propane) and hexamethylene (for hexamethylene tetramine) in Vol. 2 (pp. 476 and 37 respectively). Simple misprints, however, are not infrequent. Each of the three volumes of "Elastomers and Plastomers" is illustrated and has its own subject index; but there is no author index.

The importance of industrial plastics is so great and has increased, and is still increasing, so rapidly that the attempt in these books to co-ordinate the available information and to give a constructive review of world"wide research results and theories is praiseworthy and of great potential benefit and assistance to scientific and technical workers in this field and also to students. Furthermore, the record of problems encountered and systematically solved will provide a fascinating insight for many who have a general interest in the achievements of modern science.

D. F. Twiss

\section{CHEMISTRY, ANCIENT AND MODERN}

\section{Crucibles}

The Story of Chemistry from Ancient Alchemy to Nuclear Fission. By Bernard Jaffe. New edition, revised and enlarged. Pp. xiii +480 . (London: Hutchinson's Scientific and Technical Publications, 1949.) 18s. net.

$\mathrm{W}$ HEN "Crucibles" first appeared in 1930, it quickly achieved wide popularity, particularly in the United States. Bernard Jaffe, the author, received the Francis Bacon Award for the "Humanizing of Knowledge", and the book was reprinted several times. In the present edition, which is the third, the original text has been revised, and augmented by the addition of material describing recent advances in the study of the atomic nucleus. Apart from the final chapters on the development of nuclear studies, the original, biographical, mode of treatment has been preserved throughout. The story of chemistry is presented in terms of the work and discoveries of historically important chemists, enlivened by the background of their personal histories.

Mr. Jaffe's knowledge of the history of chemistry and of chemists is extensive, though one or two errors may be detected where he deals with borderline topics. The Watt engine, for example, is described (p. 410) as being the first successful steam engine; but the Newcomen engine was at work in the coal pits and tin mines some half a century before Watt brought out his patent. However, from a historian's point of view, the main defect of the book lies in its biographical method of treatment. We are presented with a succession of chemists rather than with the development of chemistry, and so the discoveries of the individual in some cases seem arbitrary and unrelated to the connected historical development of chemistry itself. In a sense, the development of science has always transcended the individual worker, and this becomes more evident, if not more true, the nearer we approach to the present day. Thus, in the final chapters of "Crucibles", Mr. Jaffe of necessity has placed less emphasis upon the biographical approach and treats the development of nuclear chemistry more as an organic whole, bound together by the logic of inference and experiment.

Biographies, however, provide much more detail of human interest than austere analytical works, and in this "Crucibles" excels, ranging over such topics as the usefulness of Dalton's colour-blindness and the content of Kekulé's dreams. It is a most readable work, for Mr. Jaffe has an eye for quaint detail and a style that is fast-moving, though sometimes rather sensational.

S. F. Mason

\section{HEAT TRANSFERENCE}

\section{An Introduction to Heat Transfer}

By M. Fishenden and Prof. O. A. Saunders. Pp. $x+$ 206. (Oxford : Clarendon Press ; London : Oxford University Press, 1950.) 15s. net.

Tritiof HIS concise account of the science and practice of heat transfer has been written to meet the needs of university students of engineering. When it is remembered that many of the simplest laboratory experiments on heat transfer involve some very difficult theory for even a partial explanation, it will be realized that the large-scale problems of engineering and industry are only tractable by the use of approximations of sufficient accuracy for the job in hand. This kind of work, above all, requires a firm grounding in fundamental physical principles, and the purpose of this book is to guide the reader in relating a large number of practical problems to these principles, as the first step towards their solution. The numerical examples worked out in the text form valuable illustrations of the general plan of campaign.

In the chapter on radiation, the black-body laws are adapted to practical cases, and tables of data for the emission and absorption of radiation by flames, furnace gases, ammonia and other gases are given. The straightforward work on steady-state conduction is followed by an interesting geometrical method of calculating the rate of rise of temperature at any point before the steady state is reached, and examples on this method are worked out. The dimensional treatment of both free and forced convection is fully explained; and, in the chapter on forced convection, there is a detailed study of banks and nests of pipes, with appropriate tables of figures. There are also chapters on friction in its relation to convection transfer, and on the transfer of heat from a condensing vapour and to a boiling liquid.

When Fishenden and Saunders's "Calculation of Heat Transmission" appeared in 1932, it was reviewed in these columns as an important book, by which the authors had placed workers in the field of heat very heavily in their debt. Students will surely feel the same about this present volume, which is excellent to read and is directed to their needs with distinguished skill and great experience. The development and growing importance of the subject during the past twenty years or so is evidenced by the range of titles and dates of the papers listed in the bibliographies at the ends of the several chapters. G. R. NOAKES 